\title{
New Survey Results Enhance Cuba's NCD Surveillance: Mariano Bonet MD Director, National Hygiene, Epidemiology and Microbiology Institute
}

\section{Gail Reed MS}

"The family would like you to become a doctor," were the somber words delivered by $\mathrm{Dr}$ Mariano Bonet's father at the wheel of their old Mercury ' 55 , as he drove his son along a dirt road into the Cuban countryside. At 17 , the young Bonet was trying to decide between two careers that excited him: medicine and engineering. But that drive was the turning point, and he enrolled in medical school that year.

Another turning point came in Bonet's last year of medical school, as he was making ward rounds one Saturday, looking for patients to recommend for discharge. "They were all chronically ill, with heart disease, stroke, hypertension, and I knew they would be back because the causes were in their lives, not whatever put them in the hospital. We were reaching them too late to make a real difference." This realization prompted his decision to specialize in epidemiology.

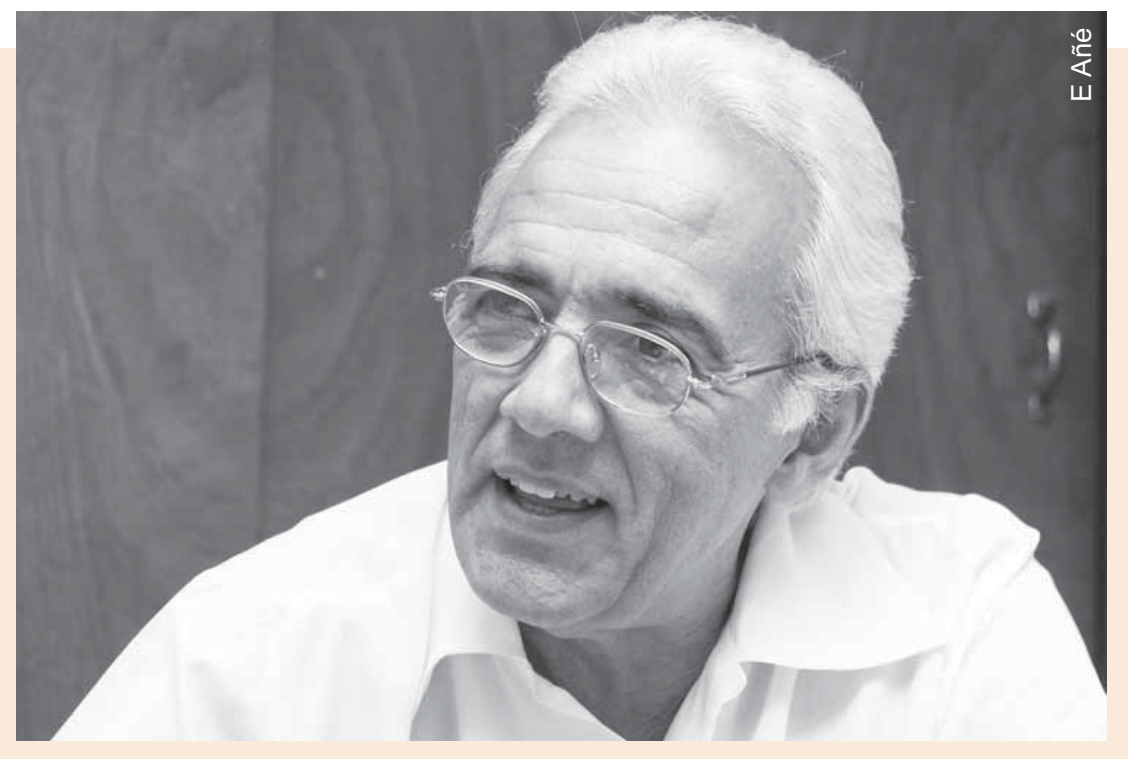

For the last 20 years, $\mathrm{Dr}$ Bonet has worked in research, prevention, and control of risk factors related to chronic noncommunicable diseases, and directed establishment of Cuba's

national surveillance system to track their trends. He led all three National Surveys on Risk Factors and Chronic Diseases (1995-96, 2001, and 2010). This September, his expertise was called upon as a member of Cuba's delegation to the UN HighLevel Meeting on Non-Communicable Diseases (NCDs). His reflections on those sessions serve as a starting point for this conversation with MEDICC Review.

\section{MEDICC Review: What were the take-away messages from the meeting?}

Mariano Bonet: The first is the leading role that governments must play in stemming the NCD pandemic - the importance of political will-because turning back the tide isn't only just a problem for the health sector, health ministries, or health professionals. Its magnitude and the fact that chronic disease risk factors are inextricably linked with all aspects of people's lives means that governments have to marshal all the agencies at their command to lead a multisectoral effort. But the fight doesn't stop there: to be effective, social actors of all kinds have to be involved: civil society, churches, communities, neighborhoods, and families themselves have to become willing, empowered participants in stopping the flood of NCDs.

The meeting also generated momentum towards action at all levels on the "big four" factors that influence NCD risk: diet (including salt and sugar consumption), physical activity, alcohol consumption, and smoking. And it reinforced the concept that all these are mediated by the social determinants of health in each particular context.

I have to say-apart from the meeting's results - that as an epidemiologist, I am optimistic about tackling NCDs precisely be- cause I think we have the opportunity as never before to educate people, to involve people, and thus generate conscious changes in behavior-still mindful of the critical role of the social determinants in NCD risk.

MEDICC Review: NCDs in Cuba are the main cause of death and disability today, and have been for some time, and there is a national program to address non-communicable diseases. Historically, how have both the evidence and the strategies evolved?

Mariano Bonet: The 1980s were a real watershed. By then, NCDs were the first cause of death in Cuba, since earlier public health actions had been successful in reducing infectious diseases, infant mortality in general, and primary and secondary care health services had been extended throughout the country; and at the same time, social determinants such as education were being forcefully addressed. We were also keenly following international developments and thinking, from the more recent results of the Framingham Study on heart disease, to the 1974 Lalonde Report and later Ottawa Charter (pioneering arguments for health promotion), and so on. Not to mention the Alma Ata Declaration, which urged development of effective health-promoting primary care throughout the world, a goal Cuba achieved in the 1970s. 
In 1983, there was even an agreement at the top levels of Cuba's leadership about the need to address the same "big four" risk factors mentioned at this September's UN meeting, an agreement that carried weight down to the provincial levels. But at the time, it didn't reach beyond the health sector: it was an idea advanced for its time, a declaration of intent.

Yet, shortly thereafter, this idea was followed by two decisions that radically changed our focus on NCDs: the first was the adoption of the family doctor-and-nurse model, locating health professionals at the neighborhood level, training them to promote health, not just treat disease. The second was the decision to launch the first NCD studies in all provinces, led by the National Hygiene, Epidemiology and Microbiology Institute (INHEM, the Spanish acronym). This also involved pooling information from a host of other agencies, such as results from earlier studies on alcohol and tobacco use conducted by the Cuban Research Institute on Consumer Demand (ICIODI, the Spanish acronym).

The big moment, however, came in 1991-92. Coinciding with the devastating economic crisis just beginning in the country, the results of those initial studies indicated that the number one causes of illness and death in Cuba were chronic noncommunicable diseases and injuries. We had to take them on, or lose the battle. So, the "Healthy People 2000" strategy was applied in a document that re-oriented the entire health system's actions (Objectives, Principles and Directives for Cuban Public Health for the Year 2000). The point was to prioritize attention to NCDs at the same level as maternal-child health and infectious diseases.

\section{MEDICC Review: From those initial studies evolved the first Na- tional Survey on Risk Factors and Chronic Diseases, correct?}

Yes, the first survey in 1995-96 was a direct result of our decision to pay more heed to NCDs: we urgently needed baseline evidence to inform strategies; to figure out what to do to address such underlying problems as hypertension, overweight and obesity; what preventive actions weren't being carried out that we needed to begin.

There have been three National Surveys on Risk Factors and Chronic Diseases over the last 15 years. Their essence is to guide more effective, targeted strategies to reduce risk factors, NCD prevalence and deaths. They allow us to see the trends, and thus evaluate how those strategies are working, correcting problems to do a better and more coordinated job.

MEDICC Review: Before we get into the actions, can you give us a bit more detail on the surveys themselves? but this time also looked at prevalence of the main NCDs and to such things as dietary preferences. The latest, conducted in 2010 and for which we are still analyzing the data, surveyed risk factors in 8,000 persons, but this time 3,000 of them in rural areas. Persons aged 15 years or older were included in the samples, since we wanted to see how lifestyles began influencing risk factors and NCDs from adolescence, so as to develop effective earlyprevention strategies. All the surveys were conducted by trained professionals of the National Statistics Office.

Simultaneously, in 2009-2010, a risk-factor study was being carried out in 17 major urban centers throughout the country-each site decided upon by provincial health authorities. These range from Guantánamo and Bayamo cities in the east to the municipality of Central Havana in the nation's capital, and Pinar del Río city in the west. The findings have helped us round out the epidemiological picture, and also to pinpoint regional, or even municipal, differences. The WHO/PAHO STEPS methodology adopted is also applicable in any province, town, or locale-so if a community polyclinic decides to study the spectrum of risk factors in their catchment area, their personnel can easily be trained to use it.

MEDICC Review: Taking the three National Surveys as reference points, what trends are you finding in, for example, tobacco and alcohol use, physical activity and diet?

Mariano Bonet: Smoking is doubtless our biggest problem, so let's look at that in more depth [See text box.-Eds.]. We're faced with many factors in breaking the smoking habit in Cuba, including the centuries-old tradition of tobacco farming and the fact that the industry is an important source of jobs and income. Nevertheless, through tougher tobacco laws and enforcement, removing cigarettes and cigars from the monthly "basket" of foods and other products at subsidized prices, and better education, we have managed to bring down the percent of smokers, and also the total number of cigarettes sold, according to the 2010 survey. While the data is preliminary, at this point we are seeing $24 \%$ of Cubans 15 years and older are smokers, compared to $32 \%$ in $2001,37 \%$ in 1995 and $68 \%$ in 1978.

Our main concern is younger people, since three quarters of smokers take up the habit in their teens.

MEDICC Review: Can you give us a preview of other trends, particularly those you find the most worrisome, encouraging, or surprising?

Mariano Bonet: The proportion of alcohol consumption (either socially or to excess) has remained relatively stable, men historically drinking more than women, and white persons drinking more than either black or mestizo Cubans. We are seeing a
Mariano Bonet: The first survey (1995-96) studied 14,500 persons in major urban centers-where $75 \%$ of Cubans live, and where the burden of non-communicable diseases is greatest-and concentrated on NCD risk factors. The second, in 2001, surveyed nearly 23,000 people in urban areas,
Selected Smoking Trends in Cuba for Persons Aged $\geq 15$ Years, 2010

\begin{tabular}{|c|c|c|c|}
\hline Sex & Age & Skin Color & Education Completed \\
\hline $\begin{array}{l}\text { Men smoke more }(31 \%) \\
\text { than women }(18 \%) \text {. } \\
\text { Women's rates are declin- } \\
\text { ing slower than men's } \\
\text { since } 1995 .\end{array}$ & $\begin{array}{l}10.4 \% \text { of those aged } 15-19 \\
\text { years are smokers. } \\
25 \% \text { of smokers start when } \\
\text { they are } 15-16 \text { years old. } \\
75 \% \text { start before age } 20 .\end{array}$ & $\begin{array}{l}\text { More black Cubans } \\
\text { smoke }(31 \%) \text { than } \\
\text { those who are white or } \\
\text { mestizo. }\end{array}$ & $\begin{array}{l}\text { Fewer university } \\
\text { graduates smoke (16\%) } \\
\text { than those completing } \\
\text { other educational levels } \\
\text { (primary, middle or } \\
\text { secondary school). }\end{array}$ \\
\hline
\end{tabular}

Source: National Surveys on Risk Factors and Chronic Diseases, 1995-96, 2001 and 2010. 
slight upward trend in drinking among women between 15 and 24 years of age.

In terms of physical activity, the preliminary data is not encouraging. While just 33\% of Cubans were sedentary in 1995 (when many of us were on bicycles and walking during the height of the economic crisis), this figure climbed to $43 \%$ in 2001 and $45 \%$ in 2010. We use an analysis that combines leisure activities with daily-life/work-related activities (including housework), and found that the majority of Cubans get most of their exercise from the latter. More women are sedentary than men, contributing to the fact that they are also more overweight: $48.3 \%$ of women in the 2010 survey were overweight.

In addition, the overweight trend has increased in the general population 15 years and older: from 32\% in 1995 to $42 \%$ in 2001 and $45 \%$ in 2010 . We have not yet started studying this phenomenon in depth in children, but obviously this needs to be done. Now the National Sports and Recreation Institute is working to generate more environments for exercise; and the labor unions are involved in a program to set up gyms in more workplaces.

Related to weight is diet, of course. Although Cubans continue to consume junk food, eat on the run, and prefer fried foods, there is some room for optimism suggested by the 2010 survey: average daily portions of fruits and vegetables have increased over 2001; salt added at the table has diminished from $24 \%$ in 2001 to just $13 \%$ of Cubans in 2010; and cooking with animal fat (lard) has decreased from $28 \%$ to $12 \%$ over the same period. Also, more Cubans are eating breakfast, instead of just drinking coffee in the morning: in 2001, one quarter of Cubans started the day without breakfast, reduced to $14 \%$ in 2010 . While encouraging, we are not yet satisfied with these results.

I should note that the 2010 survey was the first time we have studied glucose, creatinine, cholesterol and triglyceride levels nationally. The results will offer important new data.

On another front, we are perceiving hypertension as a major threat: in $1995,30.6 \%$ of Cubans in the age group studied had high blood pressure; $33.5 \%$ in 2001 ; and $30.9 \%$ in 2010 . This and smoking are the main mortality risk factors in the country. The good news here is that underdiagnosis of hypertension has been reduced, due mainly to more active screening at primary care facilities: in the 2010 survey, only $8.5 \%$ were newly discovered hypertensive patients.

Finally, over $17 \%$ of our population is already over 60 , with aging on the increase, so we are facing the prospect of ad- dressing multiple risk factors and multiple NCDs in the same person. This considerably complicates both prevention and management strategies from the health, social and economic perspectives.

\section{MEDICC Review: How does this evidence come together to inform decision-making by government, health authorities, and other sectors like agriculture, sports and education?}

Mariano Bonet: Speaking as an epidemiologist, I think the most important thing we have achieved in the last decade is consolidating our surveillance system to effectively monitor NCDs and their risk factors nationally and locally. We now have a comprehensive monitoring system that integrates information from these large surveys, plus regular reports from family physician offices; from the Ministry of Domestic Trade on alcohol and tobacco use; and from other agencies such as the National Statistics Officetaken together, providing data that are fundamental for action locally and nationally.

This information is synthesized and made available to decision makers in health at the national, provincial and municipal levels; and we are actively sharing it with other sectors. The Minister of Health and his leadership team are now working with agencies in ten other sectors to improve strategies for NCD prevention, and to promote public policies for healthier living in general.

This is a long, difficult process. It's a process that involves educating and convincing people at all levels, from high government officials to heads of households.

An omnibus proposal is now being prepared for the Council of Ministers on concrete strategies that would make each sector and ministry responsible for taking specific actions and meeting concrete targets, holding them to deadlines. This will take some time, but will be well worth the effort.

Meanwhile, we are not waiting to act: more concerted attention is already being paid to these diseases and their risk factors through generating better media messages, enforcing legislation, using leverages such as pricing, and above all, pursuing coordinated multisectoral initiatives. -1 -

(More results from the National Surveys can be found in previous articles in MEDICC Review: Overweight, Obesity, Central Adiposity and Associated Chronic Diseases in Cuban Adults in the Fall, 2009 issue; and Cubans' Deadly Diet: A Wakeup Call in the Spring, 2008 issue, Eds.)

Erratum

Pérez L, Correa C, Alemán J, González I, Pérez J, Martínez PA, Álvarez A, Soto Y, Kourí V. Drug-resistant HIV-1 in Cuban Children and their Seropositive Mothers. MEDICC Review. 2011; 13(2):24-31.

Page 31, The Authors, "Joan Alemán" should read "Yoan Alemán Campos." 